\title{
A IRRIGAÇÃO POR GOTEJAMENTO EM BERINJELA (Solanum melongena, L.) *
}

D. B. Vieira

H. A. Manfrinato

\section{RESUMO}

O presente trabalho relata os dados obtidos em um experimento de campo, onde estudou-se o efeito da irrigação por gotejamento aplicada em três niveis diferentes de intensidade de chuva em cultura de berinjela, em comparação com a irrigação por sulcos de infiltração, método tradicional para a rega dessa cultura.

Os resultados obtidos indicam que o método de irrigaçăo por gotejamento permitiu a obtenção de melhores rendimentos, em relação a utilização da irrigação por sulcos de infiltração. A irrigação por gotejamento a baixa intensidade de chuva, foi a que proporcionou os melhores rendimentos da cultura de berinjela.

\section{INTRODUÇAOO}

A cultura da berinjela vem se desenvolvendo muito no Estado de São Paulo, notadamente nos cinturões verdes próximos às grandes cidades. Embora a precipitação pluviométrica anual oscile ao redor de 1.200 milímetros, a irrigação da berinjela em São Paulo é uma necessidade, devido à má distribuição das chuvas e ao elevado consumo da água pelas plantas.

BERNARDI (1965) cita que a irrigação da berinjela é uma necessidade, devendo ser executada semanalmente e pelo método de sulcos de infiltração. Esse método da irrigação é muito pouco eficiente, induzindo elevadas perdas de água, o que é muitas vezes, uma drástica limitação para a utilização do manancial.

* Entregue para publicação em 05/04/74.

** Departamento de hidráulica e Saneamento - Faculdade de Engenharia de Limeira UNICAMP.

*** Departamento de Engenharia Rural - ESALQ, USP. 
0 método de irrigação por gotejamento surgiu de trabalhos experimentais conduzidos em Israel, os quais tinham por objetivo economizar água, o que é uma preocupação constante nesse país. Basicamente o gotejamento consta de tubulações de pequeno diâmetro às quais estão ligados gotejadores, que distribuem a água à cultura a vazão reduzida. As tubulações acompanham paralelamente a linha da cultura e de espaço em espaço, gotejadores fluem a água de irrigação. Essa maneira de irrigar mostrou-se altamente eficiente em relação aos métodos tradicionais de irrigação, propiciando assim uma grande economia de água.

Além disso, as experiências conduzidas em Israel comprovaram que o gotejamento proporciona a obtenção de maiores produções, comparativamente aos demais métodos de irrigação, sob idênticas condições. Isto se deve provavelmente, ao fato da irrigação por gotejamento não prejudicar a aeração do solo, pois o ar é muito importante à respiração das células das raízes, à absorção de nutrientes e da própria água. 0 que se comprova, pelas plantas sujeitas a longo período de enxarcamento do solo, portanto de péssimas condições de aeração, tais plantas, após alguns dias, apresentam sintomas de seca fisiológica, embora no terreno haja água em abundância.

O objetivo deste trabalho, é de verificar o comportamento da cultura da berinjela ao ser irrigada por gotejamento e pelo método tradicional de sulcos de infiltração. A irrigação por gotejamento foi executada em três níveis de intensidade de chuva.

\section{REVISÃO DE LITERATURA}

BERNARDI (1967) tecendo considerações agronômicas sobre a cultura da berinjela, afirma que a irrigação artificial dessa solanácea é indispensável, pois ela presta grande auxílio principalmente nos anos em que as chuvas são escassas ou mal distribuídas. Salienta esse pesquisador, que as irrigações devem ser feitas pelo método de sulcos de infil. tração e a intervalos de uma ou no máximo de duas semanas.

BAVER e FARNSWORTH (1947) citam, que a adequada aeração do solo é um dos fatores essenciais para o bom desenvolvimento das plantas, principalmente de seu sistema radicular. As células radiculares necessitam do oxigênio presente no ar do solo para a sua respiração, por essa razão as aplicações de fertilizantes nem sempre dão boas respostas nos solos de textura pesada os quais são geralmente mal arejados.

MANFRINATO (1970), trabalhando com tomateiros (Lycopersicum esculentum, L.) irrigados a diferentes níveis de intensidade de chuva, conclui que o tempo que decorre para efetuar a irrigação do solo, somado ao tempo gasto para a água atingir a capacidade de campo, quando se utilizam chuvas de grandes intensidades tornam-se prejudiciais às raízes. Isto se dá principalmente com respeito ao metabolismo das células das raízes, as quais são responsáveis pela passagem da maior porcentagem 
do fluxo da água do solo para o xilema, confirmando dessa maneira as citações de MEES e WEATHERLEY (1957), os quais afirmam que as perturbações nas atividades metabólicas das células da raiz, devem oferecer resistência ao fluxo através das células vivas, causando prejuízos ao crescimento da planta e à sua produção.

SWAN e COFFMAN (1971) afirmam que periodicamente as irrigações por inundação e aspersão envolvem pesadas aplicações de água, o que mantém a cuitura sob teores de umidade do solo próximos da saturação e pobres de aeraçấo. Posteriormente, ocorre um constante decréscimo nos níveis de umidade do solo desde a capacidade de campo (CC) até a porcentagem de murchamento permanente (PMP), o que causa uma mudança irregular na tensão de umidade do solo, prejudicando as plantas. Estaś afirmações, podem ser estendidas à irrigação por sulcos de infiltração que proporciona piores condições de aeração do solo comparativamente à aspersão.

Embora a irrigação por gotejamento tenha surgido em Israel, há referências de uma irrigação em gotas executada em estufas de vidro utilizada há muitos anos como atesta DUNN (1970). O que se comprova pelas experiências de FORBES (1960) pesquisando o desenvolvimento da cultura de tomateiros em estufas de vidro irrigada por gotejamento.

GOLDBERG e SHMUELLI (1970), descrevem que há alguns anos foram iniciados em Israel estudos com um sistema de irrigação subterrânea, o qual permitia a aplicação da água a pequenas vazões e próximo às raízes, de tal sorte a propiciar grande economia de água. Contudo as raízes, acabavam por penetrar no interior das tubulações, entupindo-as e conseqüentemente, comprometendo todo o sistema. Experimentaram então utilizar esse equipamento de irrigação sobre a superfície do terreno, e verificaram que essa maneira de proceder mostrou-se altamente eficiente e benéfica às plantas, surgindo então o método de irrigação por gotejamento. As principais vantagens do gotejamento são: proporciona melhores colheitas que os métodos usuais de sulcos e de aspersão; permite o cultivo em terrenos onde o sal é fator limitante; permite a utilização de águas salobras; propicia grande economia de água, etc.

GOLDBERG e SHMUELLI (1970) citam que em trabalhos experimentais com melões irrigados por gotejamento, sulcos e aspersão, obteve-se as seguintes produções: gotejamento: 39,0 ton/ha; sulcos: 21,9 ton/ha $\mathrm{e}$ aspersão: 21,6 ton/ha. REMER (1971 afirma, que em trabalhos experimentais conduzidos no deserto do Neguev em Israel, obtiveram-se aumentos dep roduções da ordem de $167 \%$ para os tomateiros, $180 \%$ para os melões, $100 \%$ para pimentões e $233 \%$ para o milho doce, quando se utiliza o gotejamento comparativamente à irrigação por sulcos e aspersão.

Esses aumentos de produção são devidos a certas características dessa irrigação, que a torna mais eficiente que as demais. Uma das características mais importante, é que no gotejamento o solo permanece insaturado e bem arejado, GOLDBERG e Al. (1971). Sendo que a tensão de umi- 
dade do solo nunca excede 0,33 atmosferas correspondente a Capacidade de Campo, GOLDBERG e GORNAT (1971).

$\mathrm{Na}$ irrigação por gotejamento pode-se utilizar recursos de água insuficientes para os demais métodos de irrigação, assinala LARKMAN (1971). Isto ocorre pois eliminam-se as perdas de água por evaporação durante a irrigação, fornecendo-se às plantas somente a quantidade exata de água por elas requerida. Aliando-se a essa característica, as qualidades desse sistema: - nessa irrigação a água não escoa pelo sulco para ser distribuída às plantas; a distribuição da água é uniforme e exata; nessa irrigação não existe o excesso de água no final do sulco, excesso esse que aumenta continuamente com a redução da infiltração do solo - verifica-se que a economia de água é uma característica do gotejamento.

NORTHCOTT e CROSS (1971) citam, que a irrigação por gotejamento mantém a zona das raízes em níveis de umidade ideais por todo o ciclo da cultura, o que é particularmente importante para as plantas muito exigentes em água. As chuvas, as irrigações por sulcos de infiltração ou outro processo convencional de irrigação permitem ótimo teor de umidade do solo, apenas periodicamente, como descreve PACKARD (1972).

\section{MATERIAL E MÉTODO}

\subsection{Material}

O presente trabalho foi desenvolvido no campo experimental da área de hidrologia afeta ao Departamento de Hidráulica e Saneamento da Faculdade de Engenharia de Limeira - UNICAMP. Tal campo experimental localiza-se no «campus» de Limeira da Universidade Estadual de Campinas, situado no bairro Jardim Nova Itália.

\subsubsection{Solo}

O solo da local pertence ao grande grupo Latossolo Vermelho Amarelo-orto sendo, portanto, profundo e argiloso. Com determinações na placa pososa a tensão de até uma atmosfera e no extrator de membrana de Richards até 15 atmosferas, obtiveram-se as relações de teor de umidade do solo em porcentagem em relação ao peso seco, com tensão de umidade do solo. Com esses resultados, apresentados no Quadro 1, traçou-se a curva característica da água do solo na figura 1. 
Quadro I: Dados de umidade do solo em porcentagem relativamente ao peso seco, submetido a diferentes tensões.

\begin{tabular}{|l|c|c|c|c|c|c|c|}
\hline \multirow{2}{*}{$\begin{array}{l}\text { Prof. } \\
\mathrm{cm}\end{array}$} & \multicolumn{7}{|c|}{ Tensão matricial em atmosferas } \\
\cline { 2 - 8 } $0-40$ & 28,0 & 25,3 & 23,2 & 23,2 & 21,5 & 20,2 & 19,3 \\
\hline
\end{tabular}

Com base na curva característica da água do solo, obteve-se o teor de umidade correspondente à porcentagem de murchamento permanente (PMP), que equivale à tensão de 15 atmosferas. A capacidade de campo (CC) e o peso específico aparente do solo seco $(\gamma)$ foi obtido pelas técnicas rotineiras. Esses dados estão no quadro 2 deste trabalho.

No quadro 3 estão apresentados os resultados da análise química do solo.

Quadro II: Dados da fisica da água do solo

\begin{tabular}{|l|c|c|c|}
\hline $\begin{array}{l}\text { Prof. } \\
\mathrm{cm}\end{array}$ & $\begin{array}{c}\text { C.C. } \\
\%\end{array}$ & $\begin{array}{c}\text { P.M.P. } \\
\%\end{array}$ & $\begin{array}{c}\gamma \\
\mathrm{g} / \mathrm{cm}^{3}\end{array}$ \\
\hline $0-40$ & 28,2 & 19,3 & 1,43 \\
\hline
\end{tabular}

Quadro III: Dados da análise química do solo.

\begin{tabular}{|l|c|r|r|r|r|c|}
\hline \multirow{2}{*}{$\begin{array}{l}\text { Prof. } \\
\mathrm{cm}\end{array}$} & $\mathrm{pH}$ & $\begin{array}{r}\text { Carbono } \\
\%\end{array}$ & \multicolumn{4}{|c|}{ Toor trocável em e.mg/100g de solo } \\
\cline { 4 - 7 } & & $\mathrm{PO}_{4}$ & $\mathrm{~K}^{+}$ & $\mathrm{Ca}^{++} \mathrm{Mg}^{++}$ & $\mathrm{Al}^{+++}$ \\
\hline $0-40$ & $\begin{array}{c}5,3 \\
\text { Médio }\end{array}$ & $\begin{array}{c}2,00 \\
\text { Alto }\end{array}$ & $\begin{array}{l}0,07 \\
\text { Baixo }\end{array}$ & $\begin{array}{c}0,29 \\
\text { Médio }\end{array}$ & $\begin{array}{c}4,50 \\
\text { Médio }\end{array}$ & 0,00 \\
\hline
\end{tabular}




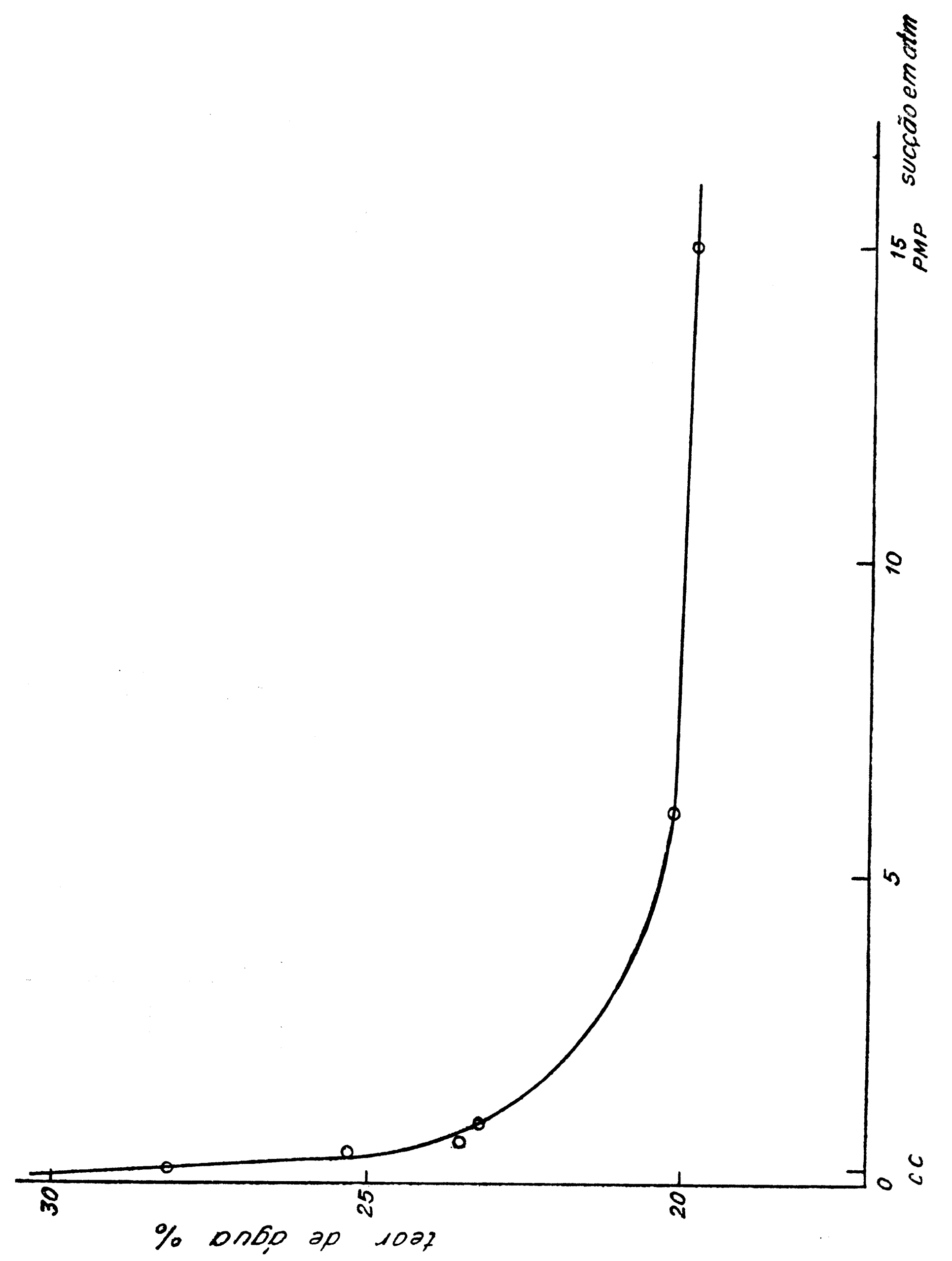




\subsubsection{Planta}

A planta utilizada no presente trabalho foi berinjela, cientificamente denominada Solanum melongena, L., da variedade IAC-3015-Santa Genebra, que é precoce e produtiva. A profundidade efetiva das raízes foi fixada em 40 centímetros com base em outras solanáceas, pois não se dispunha de dados sobre o assunto.

\subsubsection{Equipamento de gotejamento}

Por não existir no mercado um equipamento para esse tipo de irrigação, quando da implantação da pesquisa, optou-se pela construção de um equipamento na própria Faculdade. Para tanto, baseou-se no utilizado na Nova Zelândia como descreve DUNN (1970). A linha de distribuição foi construída de tubos de P.V.C. com 25 milímetros de diâmetro, na qual equidistantemente uniam-se microtubos de 2 milímetros de diâmetro. Por esses microtubos a água escoava às plantas, ao mesmo tempo que tinha a sua pressão reduzida até próximo da pressão atmosférica. 0 comprimento dos microtubos era de 50 centímetros e o espaçamento nos tratamentos de baixa e média intensidade era de 50 centímetros. No de alta intensidade o espaçamento entre microtubos era de 25 centímetros, sendo utilizados dois microtubos por planta.

Reservatórios de nível de água constante proporcionavam a pressão necessária ao funcionamento do equipamento. $O$ reservatório para o tratamento de alta intensidade de chuva mantinha o nível d'água a 5,30 metros acima da linha de distribuição. Nos de média e de baixa intensidade a altura era de 3,40 e 2,40 metros, respectivamente, sendo que neste último tratamento foi colocado um Venturi de 3 milímetros de diâmetro na mangueira de conexão entre o registro e a linha de distribuição, a fim de permitir uma vazão reduzida.

O comprimento da linha de distribuição era de 7,10 metros. 0 sistema foi calibrado antes da implantação da experiência, para garantir uma distribuição homogênea da água durante a irrigação. A figura 2 mostra um esquema do sistema utilizado. 

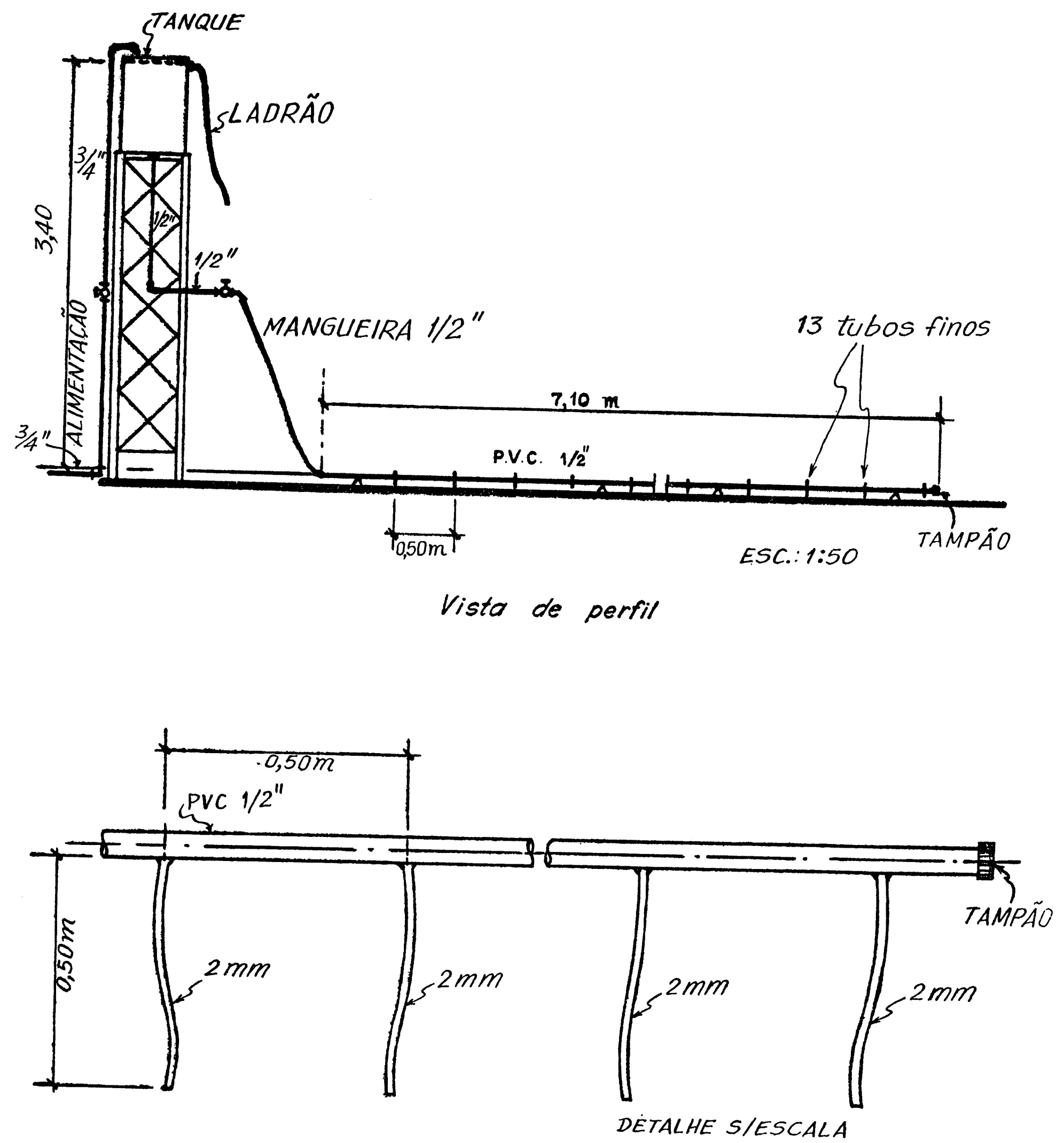

Vista de cima

Fig. 2 - Esquema geral do sistema de irrigação por gotejamento. 


\subsubsection{Sistema de irrigação por sulcos}

As dimensões dos sulcos de infiltração eram: comprimento $=7$ metros, largura $=0,30 \mathrm{~m}$ e profundidade $=0,18 \mathrm{~m}$. A declividade adotada foi $1 \%$. Sendo que vertedores triangulares garantiam a entrada de uma vazão constante nos sulcos.

\subsubsection{Abrigos}

Os tratamentos irrigados por gotejamento eram protegidos por abrigos com cobertura de lona plástica, transparente aos raios solares, a fim de que as chuvas não mascarassem o efeito dessa irrigação. A ventilação era garantida por aberturas laterais, frontais e dos fundos do abrigo.

\subsection{Métodos}

\subsubsection{Delineamento experimental}

0 delineamento adotado foi o de ensaio inteiramente ao acaso, com quatro tratamentos e vinte e seis repetições. Os tratamentos foram:

Tratamento A - irrigação por gotejamento à alta intensidade de chuva - vazão fornecida pelos gotejadores: $62 \mathrm{l} / \mathrm{h}$. Intensidade de chuva: $142 \mathrm{~mm} / \mathrm{h}$.

Tratamento B - irrigação por gotejamento à baixa intensidade de chuva. Vazão dos gotejadores: $5,2 \mathrm{l} / \mathrm{s}$. Intensidade de chuva: $10 \mathrm{~mm} / \mathrm{h}$.

Trałamento C - irrigação por gotejamento à média intensidade de chuva. Vazão dos gotejadores: $27 \mathrm{l} / \mathrm{h}$. Intensidade de chuva: $34 \mathrm{~mm} / \mathrm{h}$.

Trałamento D - irrigação por sulcos de infiltração. Vazão por sulco: $0,61 / \mathrm{s}$.

\subsubsection{Cultura}

A cultura foi planejada para o espaçamento de $1,00 \mathrm{~m}$ entre linhas e de $0,50 \mathrm{~m}$ entre plantas. A semeadura foi feita no dia 27 de setembro de 1972 em copos de papel. A germinação ocorreu a 9 de outubro e o transplante a 19 de dezembro.

Até o perfeito regamento das plantas transplantadas procedeu-se a irrigações diárias. A 2 de janeiro de 1973 iniciou-se o controle da irrigação. Todos os tratos culturais, obedeceram às recomendações de BERNARDI (1965).

\subsubsection{Quotas e controle da irrigação}

O teor de água disponível no solo foi obtido com a fórmula: 


$$
\mathrm{AD}=\frac{(\mathrm{CC}-\mathrm{PMP})}{10} \times \mathrm{h} \times \frac{100}{\mathrm{Ei}} \times \gamma
$$

sendo:

$\mathrm{AD}=$ altura de água disponível no solo, em milímetros;

$\mathrm{CC}=$ teor de umidade do solo suposto na capacidade de campo, expresso em porcentagem em relação ao piso seco;

PMP = teor de umidade do solo suposto na porcentagem de murchamento permanente, expresso em porcentagem em relação ao peso seco;

$\mathrm{h}=$ profundidade do solo em que se pretende irrigar em centímetros;

$\gamma=$ peso específico aparente do solo seco, em gramas por centímetros cúbicos;

$\mathrm{Ei}=$ eficiência da irrigação, em porcentagem.

A profundidade de irrigação (h) foi fixada em 40 centímetros com base na profundidade efetiva das raízes da cultura. A eficiência de irrigação (Ei) foi adotado: 80\% para o gotejamento e 60\% para os sulcos de infiltração.

Como a berinjela é uma planta bastante exigente em água, deixou-se um reserva de umidade no solo correspondente a $75 \%$ da água disponível. Dessa forma a altura de irrigação foi de 16 milímetros para todos os tratamento, o que corresponde aos seguintes tempos de irrigação:

Tratamento A: 8 minutos

Tratamento B: 1 hora e 36 minutos

Tratamento C: 18 minutos

Tratamento D: 1 hora.

O controle da umidade do solo nos tratamentos foi feito pelo método gravimétrico utilizando estufa regulada a $105^{\circ} \mathrm{C}$, obtendo-se teor de umidade atual do solo (Ua) expresso em porcentagem em relação ao peso seco. A transformação desse valor em altura atual de umidade do solo (H) utilizou-se a fórmula de MORETTI (1962):

$$
\mathrm{H}=\frac{(\mathrm{CC}-\mathrm{Ua})}{10} \times \mathrm{h} \times \gamma
$$

Levando-se na abcissa o tempo em dias e, na ordenada a altura atual de água disponível e construiu-se o gráfico de controle do ensaio que apa- 
rece na figura 3. A linha interrompida corresponde ao gasto de $25 \%$ da água disponível $(\mathrm{AD})$ e portanto sempre que 0 teor de umidade do solo atingir essa linha, irrigou-se.

\section{RESULTADOS E DISCUSSÃO}

A presente pesquisa teve seu encerramento no dia 3 de abril de 1973. Os resultados obtidos com relação ao número de frutos produzidos e ao peso dos frutos são mostrados nos Quadros 4 e 5 . As análises de variância desses resultados estão nos Quadros 6 e 7 .

0 método de irrigação por gotejamento permite uma consubstancial economia de água, principalmente quando comparado com a irrigação por sulcos de infiltração, podendo-se utilizar mananciais de água mais escassos, como, acentua LARKMAN (1971), que são insuficientes para os métodos convencionais de irrigação. Isto ocorre, porque as perdas de água no gotejamento são menores, conseqüentemente a eficiência da irrigação é maior. Dessa forma, o gotejamento permite a partir de um mesmo manancial a irrigação de maiores áreas, o que é particularmente importante para cultivos olerícolas. 


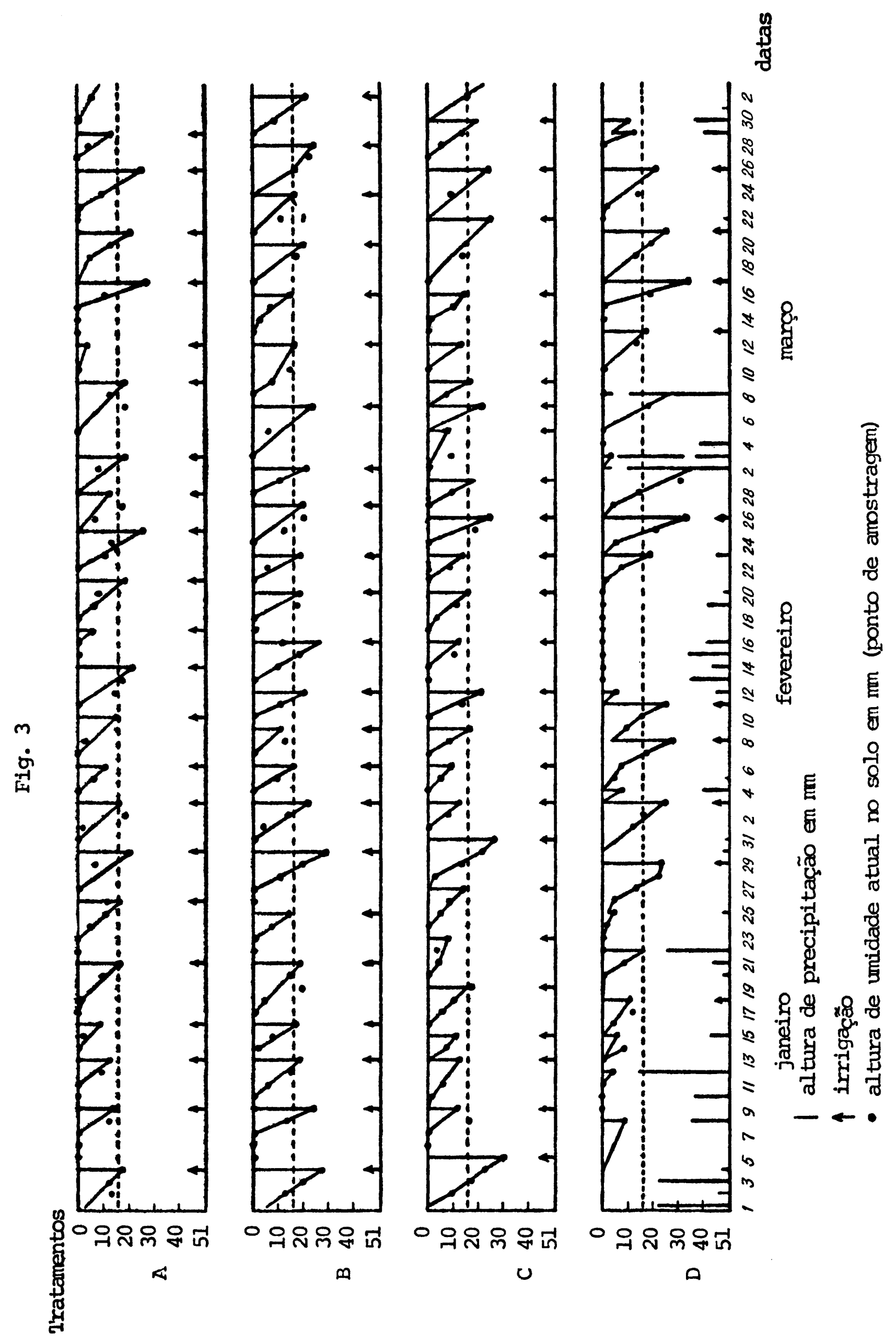


Quadro IV: Resultados da influência dos tratamentos sobro o número de frutos.

\begin{tabular}{|c|c|c|c|c|}
\hline Repetições & ALTA & BAIXA & MÉDIA & SULCOS \\
\hline 1 & 1 & 4 & 0 & 5 \\
\hline 2 & 4 & 8 & 2 & 1 \\
\hline 3 & 9 & 5 & 10 & 4 \\
\hline 4 & 10 & 13 & 7 & 7 \\
\hline 5 & 7 & 7 & 5 & 6 \\
\hline 6 & 9 & 9 & 5 & 7 \\
\hline 7 & 9 & 9 & 10 & 6 \\
\hline 8 & 6 & 5 & 4 & 6 \\
\hline 9 & 6 & 13 & 5 & 3 \\
\hline 10 & 9 & 9 & 6 & 7 \\
\hline 11 & 8 & 7 & 8 & 11 \\
\hline 12 & 8 & 9 & 8 & 2 \\
\hline 13 & 10 & 12 & 9 & 9 \\
\hline 14 & 9 & 0 & 8 & 8 \\
\hline 15 & 11 & 9 & 9 & 8 \\
\hline 16 & 12 & 9 & 9 & 5 \\
\hline 17 & 7 & 11 & 13 & 6 \\
\hline 18 & 11 & 9 & 11 & 6 \\
\hline 19 & 6 & 10 & 8 & 9 \\
\hline 20 & 7 & 17 & 10 & 5 \\
\hline 21 & 7 & 8 & 10 & 6 \\
\hline 22 & 6 & 9 & 11 & 5 \\
\hline 23 & 9 & 10 & 8 & 5 \\
\hline 24 & 12 & 8 & 4 & 2 \\
\hline 25 & 0 & 6 & 9 & 5 \\
\hline 26 & 7 & 8 & 7 & 6 \\
\hline
\end{tabular}


Quadro V: Resultados da influência dos tratamentos sobre o peso das frutas.

\begin{tabular}{|c|c|c|c|c|}
\hline$\underbrace{\text { Tratamentos }}_{\text {Repeticöes }}$ & ALTA & BAIXA & MÉDIA & SULCOS \\
\hline 1 & 224,13 & 1030,50 & 0,00 & 1489,52 \\
\hline 2 & 906,94 & 1400,34 & 478,16 & 169,52 \\
\hline 3 & 2008,01 & 868,34 & 1857,71 & 882,81 \\
\hline 4 & 2332,92 & 2714,32 & 1391,59 & 1569,65 \\
\hline 5 & 1272,29 & 1430,05 & 1112,95 & 1105,26 \\
\hline 6 & 2031,55 & 2026,09 & 678,32 & 1715,40 \\
\hline 7 & 1831,13 & 1653,22 & 2586,24 & 689,89 \\
\hline 8 & 1415,63 & 858,17 & 580,69 & 1311,77 \\
\hline 9 & 1307,05 & 2629,89 & 621,20 & 290,00 \\
\hline 10 & 1731,73 & 1325,26 & 871,29 & 1457,89 \\
\hline 11 & 1620,99 & 1465,29 & 1519,87 & 2225,66 \\
\hline 12 & 1829,78 & 1797,62 & 1709,82 & 453,89 \\
\hline 13 & 2489,52 & 2352,62 & 1978,07 & 1175,86 \\
\hline 14 & 1803,24 & 0,00 & 1110,15 & 1710,65 \\
\hline 15 & 2538,27 & 1863,10 & 1895,81 & 1422,05 \\
\hline 16 & 2731,51 & 1359,62 & 1542,45 & 1103,18 \\
\hline 17 & 1465,04 & 2041,79 & 2797,40 & 1334,98 \\
\hline 18 & 2161,27 & 2002,41 & 1948,49 & 1082,73 \\
\hline 19 & 1001,91 & 1862,38 & 1693,69 & 1277,33 \\
\hline 20 & 1221,67 & 2685,82 & 1810,29 & 1371,04 \\
\hline 21 & 1423,59 & 1659,57 & 2177,26 & 1139,59 \\
\hline 22 & 1545,38 & 1672,95 & 2425,12 & 916,10 \\
\hline 23 & 2175,33 & 1705,48 & 1151,68 & 833,59 \\
\hline 24 & 2718,03 & 1888,94 & 769,51 & 555,98 \\
\hline 25 & 0,00 & 1287,26 & 2262,53 & 909,72 \\
\hline 26 & 1533,86 & 1906,27 & 1601,24 & 925,90 \\
\hline
\end{tabular}

Quadro VI: Análise de variância com dados de número de frutos com a transformação $Y^{\prime}=$ Raiz $(Y+0.5000)$, obtidos do quadro $I V$.

\begin{tabular}{|l|c|c|c|c|}
\hline \multicolumn{1}{|c|}{ C.V. } & G.L. & S.Q. & Q.M. & F \\
\hline Tratamentos & 3 & 3.3517 & 1.1172 & $3.07^{*}$ \\
Residuo & 100 & 36.4115 & 0.3641 & \\
Total & 103 & 39.7632 & & \\
\hline \multicolumn{4}{|c|}{ Média Geral $=2,7425$} \\
\hline
\end{tabular}
$A=2,7924$
Médias de Tratamentos
$(C /$ erro $=0.1183)$
$B=2,9540 \quad C=2,7660$
$D=2,4576$ 
Quadro VII: Análise de variância com os dados de peso de frutos obtidos no quadro $V$.

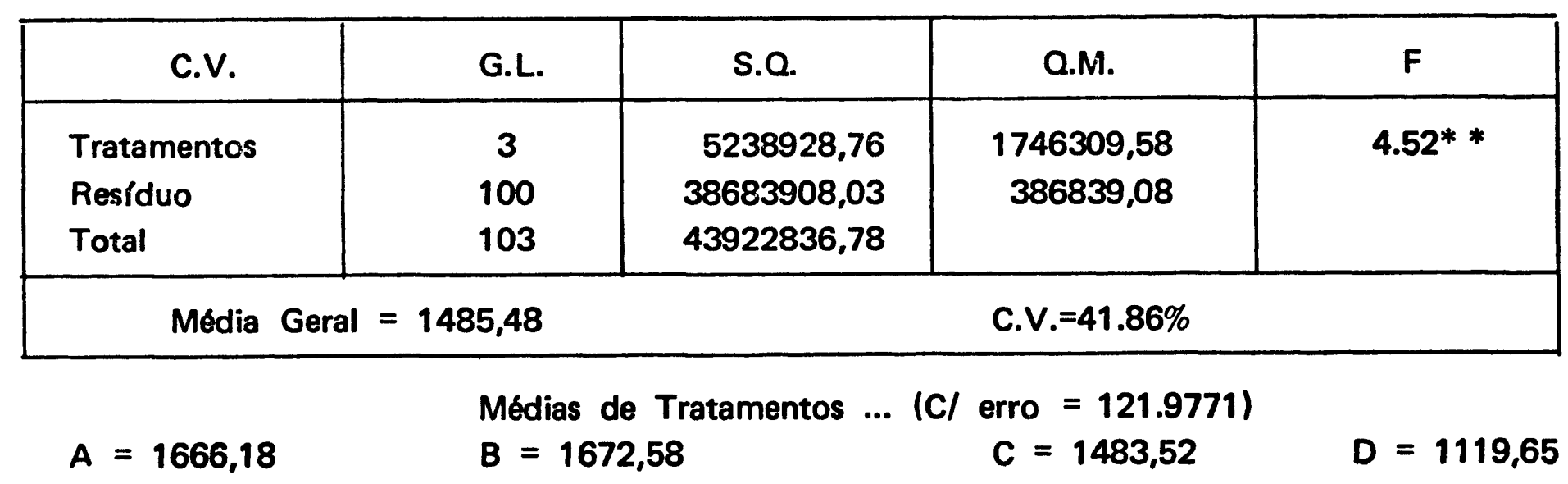

Embora normalmente a berinjela seja irrigada por sulcos de infiltração BERNARDI (1965), o gotejamento pode catalizar um maior incremento do seu cultivo. Isto porque, poderia o agricultor utilizar mananciais menos abundantes, até mesmo poços freáticos ou fontes naturais.

As citações de que a irrigação por gotejamento proporciona sob idênticas condições, a obtenção de melhores produções, são uma constante nos trabalhos científicos sobre o assunto. Para tanto basta lembrar as citações de GOLDBERG e SHMUELLI (1970) e REMER (1971), e todos evidenciando esta qualidade do gotejamento. No presente ensaio o mesmo ocorreu, no que diz respeito à análise de variância dos dados de número de frutos produzidos apresentada no Quadro 8, verifica-se que houve diferença significativa ao nível de 5\% de probabilidade entre os tratamentos. Sendo que o tratamento menos produtivo foi o de irrigação por sulcos de infiltração (D) e o mais produtivo o de irrigação por gotejamento a baixa intensidade (B). Inferindo-se que a irrigação por gotejamento a baixa intensidade de chuva é melhor para a berinjela, que a irrigação por sulcos de infiltração. 
Com relação à produção de frutos em peso, a análise de variância desses dados está no Quadro 9, e verifica-se diferença altamente significativa ao nível de $1 \%$ de probabilidade. $O$ tratamento menos produtivo foi o irrigado por sulcos de infiltração (D) e o mais produtivo o irrigado por gotejamento a baixa intensidade (B). A aplicação do Teste de Tukey deu os seguintes resultados:

$$
\begin{aligned}
& \mathrm{QM}=386839,08 \\
& \mathrm{~S}=\sqrt{386839,08}=621,96 \\
& \mathrm{~s}=\mathrm{q} \frac{\mathrm{s}}{\sqrt{\mathrm{r}}} \\
& \mathrm{QM}=\text { quadrados médios; } \\
& \mathrm{s}=\text { desvio padrão residual; } \\
& \mathrm{q}=\text { valor da amplitude total estudantizada; } \\
& \mathrm{r}=\text { número de repetições. }
\end{aligned}
$$

Os valores «q» para os níveis de $5 \%$ e $1 \%$ de probabilidade, com 100 Graus de Liberdade e 3 tratamentos foram respectivamente 3,426 e 4,333.

O cálculo de s para $5 \%$ de probabilidade deu 418,63 e para $1 \%, 529,46$.

A comparação das médias mostrou que entre os tratamentos $\mathrm{B}$ e D, gotejamento a baixa intensidade e sulcos de infiltração, as diferenças foram significativas ao nível de $5 \%$ e altamente significativa ao nível de $1 \%$ de probabilidade. A diferença entre os tratamentos A e D, gotejamento e alta intensidade de chuva e sulcos de infiltração foram significativas aos níveis de $1 \%$ e $5 \%$ de probabilidade. Estatisticamente os tratamentos melhores foram o $\mathrm{A}$ e o $\mathrm{B}$, e o pior o tratamento $\mathrm{D}$, o que confirma os resultados.

A comparação da médias obtidas nos tratamentos A e B não apresentou diferenças significativas, demonstrando que estatisticamente esses tratamentos são iguais. Contudo a produção do tratamento $\mathrm{B}$ foi superior. Considerando-se apenas as diferenças entre os tratamentos B e D, verifica-se que o gotejamento propiciou um aumento de produção de $67 \%$.

Essa maior produção de irrigação por gotejamento em relação ao método de sulcos de infiltração para a altura da berinjela, parece confirmar as citações encontradas na literatura. Deduz-se que essa maior produção foi condicionada pelas melhores condições de aeração do solo sob gotejamento. A falta de ar no solo, durante a irrigação por sulcos de infiltração, deve ter impedido que as raízes das plantas absorvessem maior quantidade dos adubos aplicados, confirmando as citações de BAVER e FRANSWORTH (1947). 
A maior produção dos tratamentos irrigados por gotejamento a baixa intensidade confirma as citações de MANFRINATO (1970) quando trabalhou com tomateiros. Ao que parece, irrigando-se por gotejamento o perfil do solo se mantém próximo da capacidade de campo sem saturá-lo, não prejudicando assim a aeração do solo, confirmando GOLDEBERG e Al. (1971). Provavelmente se a intensidade de chuva do tratamento B, fosse menor, os resultados seriam outros, pois a aeração do solo seria melhor.

Pelos resultados obtidos, deduz-se que as condições de umidade do solo, foram melhores sob gotejamento, o que confirma SWAN e COFFMAN (1971). As raízes permanecem maior tempo sem condições ideais de umidade como acentua NORTHCOTT e CROSS (1971), o que também é um fator para o melhor desenvolvimento das plantas.

\section{CONCLUSÓES}

a) $\mathrm{O}$ método de irrigação por gotejamento propiciou melhores produções de berinjela, que o de sulcos por infiltração.

b) A irrigação por gotejamento a baixa intensidade de chuva foi a que proporcionou melhores produções.

c) A irrigação por gotejamento a baixa intensidade de chuva aplicada à cultura da berinjela, condicionou um aumento de produção de $67 \%$ em comparação com a irrigação por sulcos de infiltração.

\section{SUMMARY}

\section{DRIP IRRIGATION FOR THE EGG PLANT (Solanum melongena, L.)}

This work shows the data of a field experiment of drip irrigation for the egg plant in comparison to the furrow irrigation.

The drip irrigation was applied in three different intensities: low, medium and high. thod.

The obtained data indicated better results for the drip irrigation me-

\section{LITERATURA CITADA}

BAVER, L. D. \& FARNSWORTH. Soil structure affects in the growth of sugar bets. Soil Science Society of American Proceedings. 37( ):249-256. 1947.

BERNARDI, J. B. Instruçc̃es para a cultura da berinjela. Campinas, Instituto Agronômico, 1965. 7 fls. (Mimeografado).

19(11) e 12) : 11-30. 1967. 
DUNN, J. S. Trials with trickle irrigation. Extension Bulletin of the New Zealand Agricultural Engineering Institute Lincoln College, University of Canterbury, New Zealand. 1970. $16 \mathrm{p}$.

FORBES, I. G. Developments in gorwing glass house tomatoes. New Zealand Journal of Agriculture. New Zealand. 101(5) : 459-469. 1960.

GOLDBERG, D. \& SHMUELLI, M. El riego por goteo. Un método para mayor producion agricola bajo condiciones de águas salinas e suelos adversos. Serviço de Extencion Agricola, Israel. 1970. 27 p. (Mimeografado).

. El riego por goteo. Un método apropriado para condiciocultura, Chapingo, México. 1970. 18 p. (Mimeografado).

GOLDEBERG, D., RINOT, M. \& KARU, N. Effect of trickle irrigation intervals on distribution and utilization of soil moisture in a vineyard. Soil Science of America Proccedings. 35(1) : 127-130. 1971.

GOLDEBERG D. \& GORNAT, B. Trickle irrigation. A New approach to irrigation, totally dependent on plastic polimer materials. International Comission and Drainage, Eighth Congress, Nova Delhi, India. R'14. (Question 28.1) 1971.

LARKMAN, B. H. Trickle irrigation - a new concept to mcrease profitability. The irrigation Farmer, Australia. 7(5) : 11-15. 1971.

MANFRINATO, H. A. A influência da intensidade da chuva na disponibilidade da água do solo às plantas. Tese de Livre Docência apresentada a E. S. A. «Luiz de Queiroz», U. S. P. Piracicaba. 100 p. 1970.

MEES, G. G. \& WEATHERLEY, P. E. The mechanism of water absortion by roots. Proc. Boy. Soc. B, 147-367. 1957.

MORETTI F॰, J. Cálculo da umidade do solo para projetos de irrigação. Boletim Técnico Científico. ESALQ, 8, 10 p. 1962.

NORTHCOTT, R. K. \& CROSS, D. M. Trickle irrigation. New Zealand Journal of Agriculture, New Zealand. 122(6) :20-23. 1971.

PACKARD, J. N. Trickle irrigation works for profit. The Farmer Irrigation, Australia. 1972.

REMER, E. D. Drip irrigation for vegetables. The Farmer Irrigation, Australia. 7(4) 22. 1971.

SWAN, B. \& COFFMAN, C. R. A discription of trickle irrigation. The Farmer Irrigation, Autralia. 7(6): 11-15. 1971-1972. 